\title{
Molecular identification of Fusarium species recovered from Hospital Environment in Jos, Nigeria
}

\author{
Kim GE ${ }^{1^{*}}$, Okolo OM${ }^{1^{*}}$, Unyime $\mathrm{CE}^{2}$, Umeh $\mathrm{UE}^{3}$, \\ Iheukwumere $\mathbf{C C}^{3}$ \\ ${ }^{\prime}$ Department of Medical Microbiology, College of Health Science, \\ University of Jos, Nigeria. \\ ${ }^{2}$ Department of Medical Laboratory Science, College of Health \\ Science, University of Jos, Nigeria. \\ ${ }^{3}$ Department of Biological Sciences, University of Agriculture, \\ Makurdi, Nigeria.
}

\author{
*Correspondence: \\ OkoloOMark :okolomark@gmail.com
}

\begin{tabular}{|l|l|}
\hline $\begin{array}{l}\text { Article } \\
\text { information }\end{array}$ & $\begin{array}{l}\text { Date Submitted: 2/4/2020. } \\
\text { Date Accepted: 15/5/2020 } \\
\text { Date Published: June, 2020 }\end{array}$ \\
\end{tabular}

: https://doi.org/10.46912/jbrcp.151

\begin{abstract}
Fusarium species are opportunistic fungi that play an important role in nosocomial infection. The reservoir of Fusarium species in the hospital is not well understood in our environment. Therefore, the present study sought to identify the reservoir of Fusarium species in hospital environment. Three hundred and sixty (360) samples were collected from the environment of two tertiary health care facilities $A$ and B. The sample consists of water (120), soil (120) and plants (120) which were sourced from hospital environments. Cultures of these samples were performed and polymerase chain reaction was used to confirm Fusarium species. The most predominant specie was Fusarium oxysporum Hospital A: 47(57.3\%) and Hospital B: 65(64.4\%). Most of the Fusarium isolates 92(76.7\%) were recovered from soil samples, followed by water $54(45.0 \%)$ and the least were from plants 37(30.8\%). In conclusion the present study has demonstrated that hospital environment is a reservoir for Fusarium species. However, identification of such reservoir would further enhance effective infection control measures.
\end{abstract}

Keywords: Fusarium species, Hospital environment, Opportunistic fungi, Reservoir

\section{INTRODUCTION}

$F$ usarium species are opportunistic fungi associated with nosocomial infections, especially in immunocompromised patients. ${ }^{1,2}$ Fusarium species are considered the third most common fungal genus after Candida and Aspergillus. ${ }^{3.4}$ Both the pathogenic and nonpathogenic strains of Fusarium form chlamydospores which enhance their survival in adverse conditions. ${ }^{5.7}$ Fusarium species are widely distributed in soil, plants water and air, this may be attributed to their ability to grow on a wide range of substrates. ${ }^{8,94,10-12}$ More than 50 species of Fusarium have been identified, but few of these species are known to cause human infections. The clinical form of fusarial infection depends largely on the immune status of the host and the portal of entry of the 
infection ${ }^{13,15}$ Fusarium species cause a broad spectrum of infections in humans, including superficial, (such as keratitis and onychomycosis), locally invasive or disseminated infections, with the latter occurring mostly in immunocompromised patients. It may also cause allergic diseases (sinusitis) in immunocompetent individuals, ${ }^{12,14,16,17}$ and mycotoxicosis in humans and animals following ingestion of food contaminated by toxin-producing Fusarium spp. . $^{18,19}$

In a review of over 200 cases of fusariosis, 12 species were associated with infection; Fusarium solani was the most frequent with about $50 \%$ of cases, followed by Fusarium oxysporum 20\% while Fusarium verticillioidis and Fusarium moniliforme account for $10 \%$ each. In addition, Fusarium solani is the most frequent pathogen in fusarial keratitis while $F$. oxysporum accounts for most cases of onychomycosis caused by Fusarium species. ${ }^{14,19}$ Several studies have established the genetic relatedness between Fusarium species isolated from patients and hospital environment. ${ }^{5,9,11,15,20}$ However, there are few or no documented studies on Fusarium species recovered from hospital environment and its association with nosocomial infection in Nigeria, particularly in Jos, Plateau State. We hereby report the results of a molecular study of Fusarium species in the environment of two tertiary healthcare facility in Jos, Nigeria.

\section{MATERIALS AND METHODS}

\section{Sample collection}

This study was conducted within the environment of two tertiary healthcare facilities A and B. Environmental sampling was focused on water, soil and plant samples. Twenty milliliters of water samples $(n=60)$ each was collected into sterile screw-capped universal containers from different stagnant water of hospital environments. Twenty grams of soil samples $(n=60)$ each was collected into sterile polythene bags from different point, and diseased part of 60 different plants were also collected. These samples were transported to the Laboratory for analysis.

\section{Sample processing \\ Water}

Water sample were processed by a method described by Anaissie et al., (2001). ${ }^{11}$ Briefly, 10mls of each water sample was transferred into a sterile centrifuge tube and spurn at $3500 \mathrm{G}$ for 15 minutes. The resulting pellet was resuspended in $10 \mathrm{mls}$ of sterile normal saline, then $0.2 \mathrm{ml}$ of the suspension was inoculated onto Potato dextrose agar (PDA) and Sabouraud dextrose agar (SDA) supplemented with biphenyl agent. All the culture plates were incubated for minimum of 7 days at $25^{\circ} \mathrm{C}$.

\section{Soil}

The soil samples were analyzed by a method described by Zhang et al., (2012). ${ }^{3}$ The samples were washed thrice in universal containers with $10 \mathrm{ml}$ distilled water after which $10 \mathrm{ml}$ distilled water was added and the sample vortexed. From the supernatant, $0.5 \mathrm{ml}$ was collected and inoculated onto agar medium (PDA and SDA plus biphenyl agent), and incubated at $25^{\circ} \mathrm{C}$ for a minimum of seven (7) days.

\section{Plant}

The plants were washed twice with sterile water, once with $0.1 \%$ Sodium hypochlorite (Household bleach) and rinsed with sterile water. The stem of the plants were cut using sterile surgical blades and the stem cuttings placed aseptically onto agar medium (PDA and SDA plus biphenyl agent) and incubated at $25^{\circ} \mathrm{C}$ for a minimum of seven (7) days. ${ }^{3}$

\section{Identification of Fusarium spp.}

Fusarium species were initially identified based on macroscopic characteristics carried out, pigment production and microscopic examination. Tease-mount preparation was carried out using portion of the cultures on clean grease-free glass slides with a drop of lactophenol cotton blue stain. A coverslip was placed over the preparation and examined using x10 and x40 objectives. Identification of Fusarium species microscopically was by the characteristic appearance of the macro- and microconidia, and conidiophores.

\section{Molecular identification Growth condition and DNA extraction}

All Fusarium species isolated were grown in $20 \mathrm{ml}$ of potato dextrose broth for $48 \mathrm{~h}$ at $28{ }^{\circ} \mathrm{C}$. The cultures were vortex for $10 \mathrm{~min}$ and total genomic DNA extraction from the isolates was performed using Zymo Quick-DNA kits reagents (Zymo Research Corporation, U.S.A) in accordance with the manufacturer's instructions. 


\section{PCR condition}

Polymerase chain reaction (PCR) assay optimization was performed using specific primer sequences for the internal transcribed spacer 1 and 4 (ITS 1 and ITS 4) regions; ITS1 (5'-TCCGTAGGTGAACCTGCGG-3') as forward primer and ITS4 (5'-TCCTCCGCTTATTGATATGC-3') as reverse primer.13,17,21,22 Amplification was performed in $100 \mu 1$ of reaction mixture containing 50 pmol of primers, 2.5 units of Taq DNA polymerase, 200 $\mathrm{mM}$ of each dNTP, $10 \mathrm{ml}$ of 10 PCR buffer and $0.2 \mathrm{mg}$ of template DNA. The mixture was subjected to PCR in a Thermo cycler. The PCR cycles began with an initial denaturation for $3 \mathrm{~min}$ at $95 \mathrm{C}$, followed by 30 cycles of annealing for $40 \mathrm{~s}$ at $58 \mathrm{C}$, extension for $40 \mathrm{~s}$ at $72 \mathrm{C}$ and denaturation for $40 \mathrm{~s}$ at $94 \mathrm{C}$ before a final extension for 5 min at $72 \mathrm{C}$. The PCR product obtained was run on $1.4 \%$ agarose gels, stained with ethidium bromide and visualized under a UV transilluminator.

\section{RESULT}

In this study, a total of 183 Fusarium isolates were

Table 1: Distribution of Fusarium spp isolated from two hospital environment.

\begin{tabular}{|c|c|c|}
\hline Fusarium species & Hospital A $n=180$ & Hospital B $n=180$ \\
\hline F. oxysporum & $47(57.3)$ & $65(64.4)$ \\
\hline F. solani & $20(24.4)$ & $19(18.8)$ \\
\hline F. moniliformes & $12(2.4)$ & $6(5.9)$ \\
\hline F. sporotrichoide & $2(2.4)$ & $8(7.9)$ \\
\hline F. equiseti & $1(1.2)$ & $2(1.9)$ \\
\hline F. semitectum & $0(0.0)$ & $1(0.9)$ \\
\hline Total & $82(45.6)$ & 101(56.1) \\
\hline
\end{tabular}

Table 2: Frequency distribution of Fusarium Species in relation to sources of specimen

\begin{tabular}{llll}
\hline Fusarium species & Soil $\mathbf{n = 1 2 0}$ & Water $\mathbf{n = 1 2 0}$ & Plant $\mathbf{n = 1 2 0}$ \\
\hline F. oxysporum & $73(60.8)$ & $29(24.2)$ & $10(8.3)$ \\
F. solani & $10(8.3)$ & $9(7.5)$ & $20(16.7)$ \\
F. moniliformes & $4(3.3)$ & $13(10.8)$ & $1(0.8)$ \\
F. sporotrichoide & $4(3.3)$ & $3(2.5)$ & $3(2.5)$ \\
F. equiseti & $1(0.8)$ & $0(0.0)$ & $2(1.7)$ \\
F. semitectum & $0(0.0)$ & $0(0.0)$ & $1(0.8)$ \\
\hline Total & $\mathbf{9 2 ( 7 6 . 7 )}$ & $\mathbf{5 4 ( 4 5 . 0 )}$ & $\mathbf{3 7 ( 3 0 . 8 )}$ \\
\hline
\end{tabular}

obtained from 360 specimens of plants, water and soil from two tertiary hospital environments. One hundred and eighty (180) specimens each were collected from Hospital A and Hospital B. However, Fusarium species isolated from Hospital B 101(56.1\%) were more than those isolated from Hospital A 82(45.6\%). The isolates were identified into six different species, the most predominant specie was Fusarium oxysporum 47(57.3\%) from Hospital A and 65(64.4\%) from Hospital B followed by Fusarium solani 20(24.4\%) from Hospital A and 19(18.8\%) from Hospital B, the least isolated specie was Fusarium semitectum 1(0.9\%) from Hospital B and none from Hospital A as shown in table 1.

Table 2 reveals the frequency distribution of Fusarium species based on sources of specimen. Result shows that a greater number of Fusarium species 92(76.7\%) were obtained from soil samples, followed by water specimens $54(45.0 \%)$ and the least Fusarium species $37(30.8 \%)$ came from Plant specimens.

A PCR product from two Fusarium species was amplified using primer pair ITS1 and ITS4. Fusarium oxysporum was identified at approximately $530 \mathrm{bp}$ band region, $F$. solani species complex $420 \mathrm{bp}$ as presented in figure 1 .

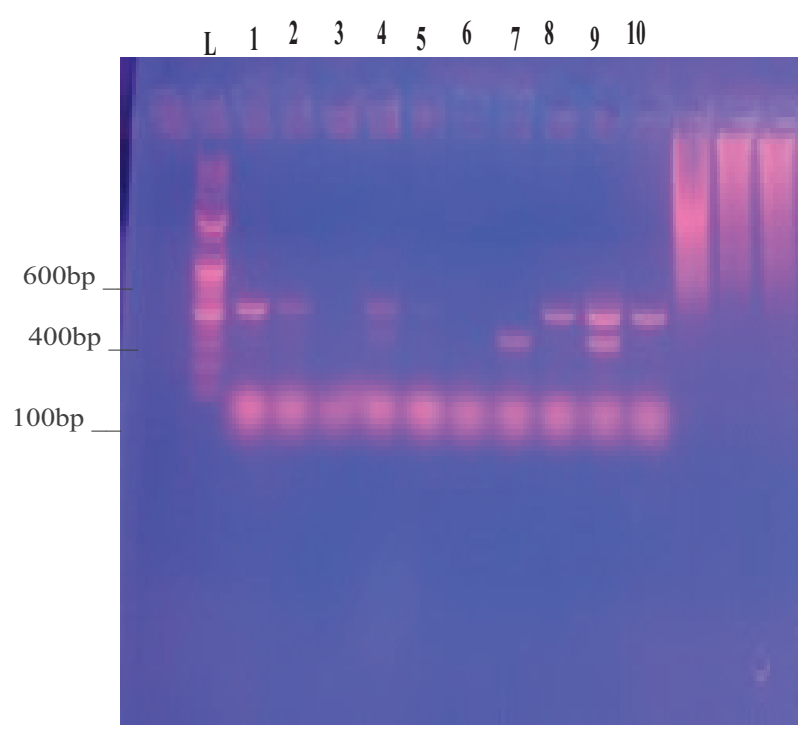

Figure 1. Conventional PCR using primers ITS1 and ITS4. Lane L, 100-bp DNA ladder. Lanes 1,2,4,8,9,10 are $F$. oxysporum. Lanes 4, 7, 9 are $F$. solani. 


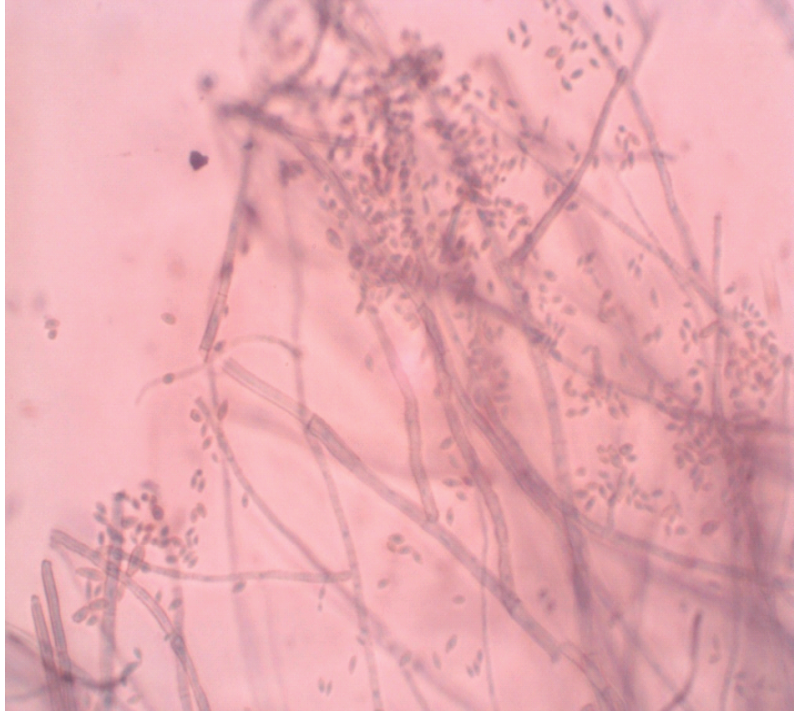

Figure 2: Microscopic morphology of Fusarium spp (magnification X400)

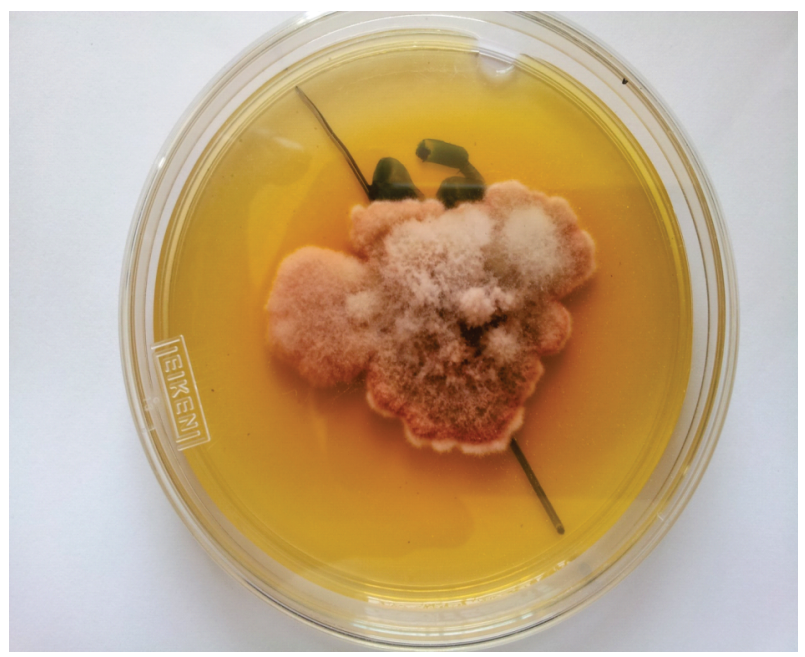

Figure 3. Potato dextrose agar plate showing the morphology of Fusarium spp

\section{DISCUSSION}

This study was conducted to demonstrate that hospital environment can be a reservoir for opportunistic fungi. Samples of soil, water and diseased plants yielded 183 Fusarium isolates. Based on their morphological characteristics these isolates were identified as $F$. oxysporum, F. solani, F. moniliformes, F. sporotrichioides, F. equiseti, F. semitectum. The isolation of these Fusarium species in hospital environments is an indication of its possible reservoir for contamination of hospital, ${ }^{5,11,22}$ surfaces that could result in nosocomial infections.

However, the isolation of these species of Fusarium in this study is similar to findings from several studies elsewhere that linked the possibility of nosocomial spread by molecular epidemiologic techniques. ${ }^{13,13,23,24}$

This study also reveals that the isolation of Fusarium oxysporum 47(57.3\%) and Fusarium solani 20(24.4\%) may be explained by the fact that their spores survive longer in water, soil and equally infect plants. ${ }^{3,25,26}$ Similar findings were reported by Scheel et al. in which Fusarium oxysporum species complex (FOSC) and Fusarium solani species complex (FSSC) were mainly isolated from hospital environment samples. . $^{13}$ Several other studies carried out in hospitals showed higher isolation rate for both Fusarium solani and Fusarium oxysporum. ${ }^{6,7,14,21}$

Based on water source, $F$. oxysporum was the most predominant isolates $29(24.2 \%)$ followed by $F$. moniliformes $13(10.8 \%)$, this finding is in tandem with the report of Anaissie et al., (2001) who documented the persistence of the spores of these species in water. And the reason for this may be due to the fact that their spores are lighter and can spread easily on water. ${ }^{5,11}$ Considering the isolation of Fusarium species from infected/diseased plants from hospital environment, $F$. solani was most predominant followed by $F$. oxysporum. Several studies have shown that plants can be infected by Fusarium species. $^{3,4,6,21,27}$

Regarding soil samples, $F$. oxysporum was the most recovered isolates $73(60.8 \%)$ followed by $F$. solani $10(8.3 \%)$. On the contrary, few studies have documented F. solani species complex as the most frequently isolated specie. ${ }^{24,28,29}$ This difference in the species isolated may be due to variation in geographical location of the studies.

\section{CONCLUSION}

In conclusion, we have demonstrated that soil, water, and diseased plants, within hospital environment are reservoirs for Fusarium species. However, this will go a long way to enhance infection control measures against opportunistic fungi. 


\section{REFERENCES}

1. Nucci M, Anaissie E. Cutaneous infection by Fusarium species in healthy and immunocompromised hosts: implications for diagnosis and management. Clin Infect Dis. 2002;35(8):909-20.

2. Nucci M, Anaissie E. Fusarium infections in immunocompromised patients. Clin Microbiol Rev. 2007;20(4):695-704.

3. Zhang M, Wang Y, Wen CY, Wu HY. First Report of Fusarium proliferatum Causing Fruit Rot of Winter Jujube (Zizyphus jujuba) in Storage in China. Plant Dis. 2012 ;96(6):913.

4. Mehl HL, Epstein L. Fusarium solani species complex isolates conspecific with Fusarium solani f. sp. cucurbitae race 2 from naturally infected human and plant tissue and environmental sources are equally virulent on plants, grow at 37 degrees $\mathrm{C}$ and are interfertile. Environ Microbiol. 2007;9(9):2189-99.

5. Mehl HL, Epstein L. Sewage and community shower drains are environmental reservoirs of Fusarium solani species complex group 1, a human and plant pathogen. Environ Microbiol. 2008;10(1):219-27.

6. Chehri K, Salleh B, Yli-Mattila T, Reddy KRN, Abbasi S. Molecular characterization of pathogenic Fusarium species in cucurbit plants from Kermanshah province, Iran. Saudi J Biol Sci. 2011;18(4):341-51.

7. Barik BP, Tayung K. Molecular differentiation of Fusarium spp. with varied lifestyles based on TEF 1 alpha gene sequence analysis. Interdiscip Sci Comput Life Sci [Internet]. 2012;4(3):201-8. Available from: https://doi.org/10.1007/s12539-012-0128-7.

8. Bogale M, Wingfield BD, Wingfield MJ, Steenkamp ET. Species-specific primers for Fusarium redolens and a PCR-RFLP technique to distinguish among three clades of Fusarium oxysporum. FEMS Microbiol Lett. 2007;271(1):27-32.

9. Seress L, Abraham H, Doczi T, Pokorny J, Klemm J, Bakay RA. Axosomatic synapses on granule cells are preserved in human non-infiltrating tumour or lesionrelated and mesial temporal sclerotic epilepsy, but markedly reduced in tumour-infiltrated dentate gyrus with or without epilepsy. Prague Med Rep.

2004;105(4):357-68.

10. Doczi I, Dosa E, Varga J, Antal Z, Kredics L, Nagy
E. Etest for assessing the susceptibility of filamentous fungi. Acta Microbiol Immunol Hung. 2004;51(3):271-81.

11. Anaissie EJ, Kuchar RT, Rex JH, Francesconi A, Kasai M, Muller FM, et al. Fusariosis associated with pathogenic fusarium species colonization of a hospital water system: a new paradigm for the epidemiology of opportunistic mold infections. Clin Infect Dis. 2001;33(11):1871-8.

12. Poli A, Bertetti D, Rapetti S, Gullino ML, Garibaldi a. Characterization and Identification of Colombian Isolates of Fusarium Oxysporum $f . S p$. Dianthi. J Plant Pathol [Internet]. 2013 Feb 23;95(2):255-63. Available from: http://www.jstor.org/stable/23721516

13. Scheel CM, Hurst SF, Barreiros G, Akiti T, Nucci M, Balajee SA. Molecular analyses of Fusarium isolates recovered from a cluster of invasive mold infections in a Brazilian hospital. BMC Infect Dis. 2013;13:49.

14.Richardson M, Lass-Florl C. Changing epidemiology of systemic fungal infections. Clin Microbiol Infect. 2008;14 Suppl 4:5-24.

15. Kover F, Schwarcz A, Pal J, Bogner P, Vajna T, Vadon $\mathrm{G}$, et al. Fast method for longitudinal relaxation time and water content mapping of the human brain on a clinical MR scanner. Acta Neurochir (Wien). 2004;146(12):1341-6; discussion 1346.

16. Godoy P, Nunes E, Silva V, Tomimori-Yamashita J, Zaror L, Fischman O. Onychomycosis caused by Fusarium solani and Fusarium oxysporum in Sao Paulo, Brazil. Mycopathologia. 2004;157(3):287-90.

17. Ninet B, Jan I, Bontems O, Lechenne B, Jousson O, Lew D, et al. Molecular identification of Fusarium species in onychomycoses. Dermatology. 2005;210(1):21-5.

18. Munkvold GP. Fusarium Species and Their Associated Mycotoxins. Methods Mol Biol. 2017;1542:51-106.

19. Dignani MC, Anaissie E. Human fusariosis. Clin Microbiol Infect. 2004;10 Suppl 1:67-75.

20. Vajda Z, Sulyok E, Doczi T, Nielsen S. Intravenous fluids for seriously ill children. Vol. 363, Lancet (London, England). England; 2004. p. 241; author reply 242 .

21.Chehri K. Molecular identification of 
entomopathogenic Fusarium species associated with Tribolium species in stored grains. J Invertebr Pathol. 2017;144:1-6.

22. Park BJ, Pappas PG, Wannemuehler KA, Alexander $\mathrm{BD}$, Anaissie EJ, Andes DR, et al. Invasive nonAspergillus mold infections in transplant recipients, United States, 2001-2006. Emerg Infect Dis. 2011;17(10):1855-64.

23. Godoy P, Cano J, Gene J, Guarro J, Hofling-Lima AL, Lopes Colombo A. Genotyping of 44 isolates of Fusarium solani, the main agent of fungal keratitis in Brazil. J Clin Microbiol. 2004;42(10):4494-7.

24. Palmero D, Rodriguez JM, de Cara M, Camacho F, Iglesias C, Tello JC. Fungal microbiota from rain water and pathogenicity of Fusarium species isolated from atmospheric dust and rainfall dust. J Ind Microbiol Biotechnol. 2011;38(1):13-20.

25. O'Donnell K. Ribosomal DNA internal transcribed spacers are highly divergent in the phytopathogenic ascomycete Fusarium sambucinum (Gibberella pulicaris). Curr Genet [Internet]. 1992;22(3):213-20. Available from: https://doi.org/10.1007/BF00351728

26. Qiu M, Zhang R, Xue C, Zhang S, Li S, Zhang N, et al. Application of bio-organic fertilizer can control Fusarium wilt of cucumber plants by regulating microbial community of rhizosphere soil. Biol Fertil Soils [Internet]. 2012;48(7):807-16. Available from: https://doi.org/10.1007/s00374-012-0675-4

27. Mehl HL, Epstein L. Identification of Fusarium solani f. sp. cucurbitae Race 1 and Race 2 with PCR and Production of Disease-Free Pumpkin Seeds. Plant Dis. 2007;91(10):1288-92.

28. Zhang Y, Ma L-J. Deciphering Pathogenicity of Fusarium oxysporum From a Phylogenomics Perspective. Adv Genet. 2017;100:179-209.

29. Waldron BL, Moreno-Sevilla B, Anderson JA, Stack RW, Frohberg RC. RFLP Mapping of QTL for Fusarium Head Blight Resistance in Wheat. Crop Sci [Internet]. 1999;39(3):cropsci1999.0011183X003900030032x. Available from: https://acsess.onlinelibrary.wiley.com/doi/abs/10.21 35/cropsci1999.0011183X003900030032x. 